\begin{tabular}{|l|l|l|}
\hline & \\
PUCRS & HUMANIDADES & $\begin{array}{l}\text { Educação por escrito, Porto Alegre, v. 12, n. 1, p. 1-13, jan.-dez. } 2021 \\
\text { e-ISSN: 2179-8435 }\end{array}$ \\
\hline dit $h$ http://dx.doi.org/10.15448/2179-8435.2021.1.33403 & \\
\hline
\end{tabular}

SEÇÃO: ARTIGOS

\title{
Estado federado e regime de colaboração na gestão de políticas educacionais
}

\section{Federal State and collaboration scheme in the management of educational policies}

\section{Raimunda Maria da Cunha Ribeiro ${ }^{1}$ orcid.org/0000-0001-6196-731X raicribeiro@hotmail.com}

Recebido em: 21/10/2019. Aprovado em: 05/04/2021. Publicado em: 23/07/2021.

\begin{abstract}
Resumo: O federalismo é um sistema político em que os entes federados se unem para formar o Estado, dotados de autonomia. Pautamo-nos, neste estudo, pelos seguintes objetivos: conceituar e caracterizar o Estado federal e as especificidades do federalismo brasileiro à luz das constituições republicanas; apresentar um quadro teórico acerca da repartição de competências em relação à gestão da educação no Brasil, tendo como dispositivo legal as constituições republicanas. A metodologia adotada foi a abordagem qualitativa de caráter descritivo e interpretativo, com base na pesquisa bibliográfica. O Estado brasileiro adota o modelo de descentralização política e administrativa, fundamentado na repartição de competências de seus entes federados. O projeto de educação do Estado federativo brasileiro tem sido marcado por um perfil ora democrático ora centralizador, seguindo os paradigmas político-administrativos de Estado no periodo republicano.
\end{abstract}

Palavras-chave: Federalismo. Gestão. Educação. Regime de colaboração.

Abstract: Federalism is a political system in which the federated entities unite to form the State, endowed with of autonomy We aim, in this study, for the following objectives: to conceptualize and characterize the federal state and the specificities of Brazilian federalism in light of the republican constitutions; to present a theoretical framework about the distribution of competences in relation to the management of education in Brazil, having as legal device the republican Constitutions. The methodology adopted was the qualitative approach of descriptive and interpretative character, based on bibliographical research. The Brazilian State adopts the model of political and administrative decentralization, based on the division of powers of its deferred entities. The education project of the Brazilian federal state has been marked by a now democratic or centralizing profile, following the state political-administrative paradigms in the republican period. Keywords: Federalism. Management. Education. Regime of collaboration.

\section{Introdução}

Estado é uma instituição com poder soberano para governar um povo no âmbito de uma área territorial; uma instituição social que mantém monopólio sobre o uso da força; é definido por sua autoridade para gerar e aplicar poder coletivo; é organizado em torno de um conjunto de funções sociais, incluindo manter a lei, a ordem e a estabilidade; tem o dever de cuidar do bem-estar da população (JOHNSON, 1997). Implica dizer, pois, que o Estado é formado de um conjunto de instituições no campo político e administrativo para organizar e manter organizada a vida de um povo. Estado e governo não significam a mesma coisa, pois, enquanto Estado, segundo Jonhson (1997), é uma instituição que consiste 
em um plano social com várias funções a serem desempenhadas, o governo é um conjunto de pessoas, em qualquer dado tempo, que ocupa funções de autoridade dentro do Estado. Destas definições podemos extrair, pelo menos, três elementos indispensáveis para que o Estado exista: povo, território e governo.

Este artigo tem como escopo discutir o modelo de Estado federativo brasileiro, formado pela união indissolúvel dos entes federados, conferida pela Constituição Federal de 1988. No contexto dessa discussão, emerge a seguinte pergunta investigativa: quais os conceitos e as características do estado federal, as particularidades do modelo brasileiro e as suas implicações na gestão das políticas educacionais? Pautamo-nos, assim, pelos seguintes objetivos: conceituar e caracterizar o Estado federal e as especificidades do federalismo brasileiro à luz das constituições republicanas; apresentar um quadro teórico acerca da repartição de competências em relação à gestão da educação no Brasil, tendo como dispositivo legal as constituições republicanas.

A metodologia adotada se pauta pela abordagem qualitativa de caráter descritivo e interpretativo, com base na pesquisa bibliográfica, cuja finalidade é reunir informações e dados para dar sustentação teórica à construção do estudo ora proposto. O artigo está dividido em duas seções: a primeira diz respeito ao Estado federativo brasileiro, em que fazemos um estudo teórico sobre as concepções de Estado e, na teia da discussão, apresentamos o modelo federativo brasileiro, as especificidades históricas e a repartição de competências, em conformidade com as constituições republicanas. Para estruturar esta seção buscamos fundamentos nos textos legais das Cartas (1981, 1934, 1937, 1946, 1967, 1988), assim como, nos escritos de Hobbes (1979), Karl Marx (1993), Locke (1955), Carnoy (2013), Gramsci (1971), Abrucio (2010), Motta (2008), Kelsen (1998), Horta (1985), Saldanha (2009), Rezende e Afonso (2004), e Ferreira Filho (2005), em atendimento ao primeiro objetivo proposto para este estudo; e, a segunda seção, trata sobre o federalismo e o regime de colaboração na gestão educacional. Para estruturá-la, nos fundamentamos nos textos legais das Cartas (1891, 1934, 1937, 1046, 1967. 1988) sobre a repartição de competências em matéria de educação, assim como nos escritos de Shiroma, Moraes e Evangelista (2004), Faleiros (2009), Ghiraldelli Jr. (2009), Ferraz (1988), Vieira (2007), Horta (1985) e Kelsen (1998).

\section{O Estado federativo brasileiro}

A Constituição da República Federativa do Brasil de 1988, seguindo uma tradição das Cartas republicanas, adota a forma federalista de organização político-administrativa de Estado, na qual prevalece a prerrogativa constitucional de repartição de competências entre os entes federados. Considerando que este artigo tem como escopo discutir o modelo de Estado federativo brasileiro e suas implicações na gestão da educação, achamos oportuno tecer algumas considerações acerca das concepções de Estado, sob a perspectiva de teorias sociopolíticas e administrativas, tendo como exemplo: a contratualista, de Estado burguês, a liberal, a marxista, de Estado unitário e Estado federado.

Em Hobbes (1979), vemos um conceito de Estado baseado na teoria contratualista, tendo em vista estabelecer um arrefecimento da turbulência social, com o fim de promover o desenvolvimento da paz social, bem como organizar, por vias do Leviatã, ${ }^{2}$ uma espécie de ordem social e política. É o Estado visto como promotor da estabilidade entre os homens, ou seja, o Estado usaria todo o seu poder através das instituições e das ferramentas administrativas para sustentar a ordem.

Sob o ponto de vista da teoria de Karl Marx (1993), o Estado é a forma final do poder; é um destacamento avançado da burguesia, um defensor, exclusivamente dos interesses da classe dos dominantes, cujo objetivo principal é o de manter-se no controle sobre a sociedade. Este Estado - burguês - não é mais que a forma de organização que os burgueses adotam para garantia reciproca de sua propriedade e de seus interesses. Marx fundamenta

2 Leviatã ou matéria, forma e poder de um Estado eclesiástico e civil, trata da estrutura da sociedade organizada (HOBBES, 1979). 
sua definição de Estado apoiado nas dimensões política e econômica para compreender o estado burguês como uma expressão das relações de produção especificas do capitalismo. Por isso, sua teoria defende que o Estado é uma instituição a favor dos interesses da classe dominante.

A teoria de Estado, defendida por Locke (1955), é tipicamente burguesa, na defesa dos principios do liberalismo. Segundo Carnoy (2013), Locke concordando com Hobbes, argumenta que os homens se juntam na sociedade política, como um corpo de leis que regem as relações de poder entre eles. Assim, nesta sociedade política, os homens entregam os direitos de autopreservação da propriedade à comunidade (O Estado). Locke, em sua definição de Estado, exclui os que não possuem propriedade; diverge de Hobbes quanto à natureza do soberano, isto é, para Hobbes, o Estado surge de um contrato, entretanto, sendo esse absoluto. Já na concepção de Locke, o Estado não poderá ser absoluto, pois esse exclui a monarquia absoluta de qualquer forma aceitável de governo.

Gramsci desenvolve o conceito de Estado apoiando-se na teoria marxista, uma vez que seu pensamento está enraizado em Marx e Lenin (CARNOY, 2013). Para Gramsci (1971), o Estado é o produto da correlação de força que atende aos interesses da burguesia como também da classe trabalhadora e, a manutenção do poder está na capacidade de equilibrar as forças. Apesar de Gramsci apoiar sua teoria nos fundamentos marxistas, elabora sua definição de Estado de forma diferente. Assim, na teoria gramsciana, o Estado como superestrutura torna-se variável essencial na compreensão da sociedade capitalista. Ele incorpora o aparelho da hegemonia tanto no Estado quanto na sociedade civil, para mostrar que o Estado é mais que um instrumento coercitivo da burguesia (CARNOY, 2013). O Estado é, pois, "todo o conjunto de atividades teóricas e práticas com as quais a classe dirigente justifica e mantém não somente a sua dominação, mas também, consegue obter o consenso ativo dos governos" (GRAMSCl, 1971, p. 244).

São teorias, do ponto de vista sociológico e político, cujo objetivo é explicar o Estado moder- no como uma organização institucional onde as forças politicas, econômicas e sociais se encontram. O Estado, segundo Motta (2008, p. 220), é a "superestrutura administrativo-organizacional que orienta e executa o cumprimento da vontade constitucionalmente manifestada", pois esse exerce o poder conferido pela Constituição e, com base nessa prerrogativa, organiza e cria suporte administrativo para desempenhar suas tarefas.

Do ponto de vista administrativo, político e financeiro, o Estado pode assumir duas posições divergentes: estado unitário (centralizado) e estado federado (descentralizado). O estado unitário é uno, ainda que se possa subdividir em regiões, em provincias ou ainda em departamentos. O estado federado é soberano constituido de estados-membros, dotados de autonomia, mas não de soberania.

A Constituição Federal de 1988 define no Art. 1. ${ }^{\circ}$ que o Brasil é um Estado federado, formado pela união indissolúvel dos Estados e Municípios e do Distrito Federal, cabendo nestes termos, à União o papel soberano frente às questões do Estado Nacional.

No federalismo vigoram os princípios de autonomia dos governos subnacionais e de compartilhamento da legitimidade e do processo decisório entre os entes federados (ABRUCIO, 2010). Em definição elaborada por Houaiss e Vilar (2001), este modelo remete à ideia da união instituida entre Estados independentes para formar uma única entidade soberana. Os entes federados são administrados a partir do pacto federativo, uma forma de regime de colaboração na elaboração e na execução das políticas públicas entre os entes federados (governo central e governos subnacionais - estaduais, municipais e distritais). O regime de colaboração é uma espécie de contrato federal, que segundo Soares (1997), significa o acordo entre as diversas comunidades territoriais para a formação de uma comunidade política mais ampla. Dizemos, pois, que as comunidades transferem parte dos seus poderes para um centro político nacional, que há consenso entre os entes federados em relação às políticas que estabelecem a comunidade política e 
que há garantia constitucional e institucional de autonomia para cada ente federado, para assim, constituir seus governos.

Ao contrário do Estado unitário, cujo governo central é anterior e superior às instâncias locais, e as relações de poder obedecem a uma lógica hierárquica, no federalismo prevalecem os principios de autonomia dos governos subnacionais e do processo decisório entre as instâncias federadas (ABRUCIO, 2010). Implica dizer, que no Estado federado o governo central e os governos locais são independentes entre si e soberanos em suas respectivas jurisdições, ou seja, esses são atores políticos autônomos com capacidade para implantar suas próprias políticas (ARRETCHE, 2002).

Motta (2008) explica, tomando como exemplo o caso brasileiro, que a regra é a existência de duas espécies de ordens juridicas: uma central (a União) e várias ordens parciais ou regionais (os Estados-membros), sendo que o Brasil admite ainda a figura do município, conforme Art. 18 da Constituição Federal de 1988. E, neste entendimento, o autor enumera três elementos indispensáveis para que exista um Estado federal: a) distribuição ou repartição constitucional de competências (descentralização política); b) participação das vontades dos centros parciais na vontade do centro principal, o que se obtém através do Senado (Câmara Alta), no bicameralismo; e c) possibilidade de autoconstituição (representada pelas constituições estaduais) (MOTTA, 2008, p. 231-232).

O debate sobre federalismo, segundo Garcia (2002), em razão da extensão territorial do País, a par das lutas históricas do processo de consolidação das fronteiras geográficas, constitui um capítulo especial de construção da nacionalidade. A estruturação do federalismo no Brasil mescla-se com a sua própria formação, passando por questões como as desigualdades regionais, a fragmentação do sistema político, as dificuldades de representação e a indefinição da estrutura e dos limites da ação estatal e a divisão de atribuições entre os entes federados (SOUZA; FARIA, 2003).

O debate sobre as especificidades do federalismo brasileiro nos permite levar em conside- ração uma questão fundamental: o princípio da descentralização do exercício do poder político consubstanciado por uma ordem jurídica única.

Kelsen (1998) e Horta (1985) argumentam, nesta perspectiva, que a descentralização implica a repartição de poderes: de um lado encontra-se a esfera federal e de outro lado encontram-se as unidades autônomas que possuem relativa independência, autonomia, política organizacional e financeira. Essa descentralização garante a repartição da estrutura do poder federal e, com efeito, garante a repartição de poderes entre os vários niveis de competências que, por sua vez, possuem autonomia organizacional, financeira e político-administrativa. A descentralização política e a tendência pluralista tornam este modelo de Estado mais democrático, já que a soberania pertence ao todo. A diversidade resulta em um pluralismo juridico que admite legislações diferenciáveis às partes especificas de cada estado-membro, desde que permitida a Constituição (SALDANHA, 2009). Vale ressaltar que a União é pessoa juridica e representa a unidade dos interesses exclusivamente nacionais, assim como no contexto das relações diplomáticas com outros paises. Afirma a autora que o "Estado federal possui a peculiaridade subsidiária de se transformar em agente regulador da convivência harmônica entre grupos territoriais reunidos por um pacto federativo, nacional e perpétuo" (SALDANHA, 2009, p. 334).

Em 1822, quando o Brasil se torna independente de Portugal, adota a forma de Estado unitário, com um governo central com grandes poderes sobre as provincias e as municipalidades (ABRÚCIO, 2010). Mesmo com a independência e a Constituição de 1824, o Brasil mantém a mesma lógica administrativa como fora na Colônia, as provincias permanecem como divisão territorial, assim como o poder centralizado nas mãos do governo central. Com a Proclamação da República, em 1889, o Brasil adota o modelo federativo, a partir do qual o País estrutura-se sobre as bases da experiência dos norte-americanos (ARAUJO, 2013). Um novo modelo de Estado, cujo nascimento deriva de uma construção política da elite dominante e conservadora da época. 
O federalismo no Brasil é introduzido ao tempo que se torna uma República, via Decreto n. 1 de 15 de novembro de 1889 do "Governo Provisório da República dos Estados Unidos do Brazil", o qual determina no Art. 1. : "Fica proclamada provisoriamente e decretada a forma de governo da nação brasileira - a República Federativa".(BRASIL, 1889).

O decreto tem como finalidade, neste sentido, promover a descentralização do Estado, cujo propósito é garantir às Provincias funções executivas e legislativas, embora o poder político continue nas mãos do governo central. Um modelo com pendência para o federalismo dual (SALDANHA, 2009).

No federalismo dual, o poder é rigidamente dividido entre a União e os estados, ou seja, os assuntos de âmbito nacional ficam a cargo da União e os assuntos de âmbito regional e local ficam a cargo dos estados. A Constituição de 1891, no Art. $5 .^{\circ}$ nos dá indicativos de federalismo dual quando expressa: "incumbe a cada Estado prover, a expensas próprias, as necessidades de seu Governo e administração; a União, porém, prestará socorros ao Estado que, em caso de calamidade pública, os solicitar" (BRASIL, 1891). Expressa, portanto, a Carta, o regime de separação de fontes tributárias e de competências entre a União e os Estados. A Constituição de 1891 traz consigo mudanças significativas em relação a estrutura do Estado brasileiro, dentre as quais podemos destacar pelo menos três: a) quanto à forma de governo: da monarquia para a república; b) quanto ao sistema de governo: do parlamentarismo para o presidencialismo; e c) quanto à forma de Estado: de Estado unitário para Estado federativo.

A evolução histórica do federalismo brasileiro nos leva a identificar as modificações imperativas de um processo cíclico de centralização do poder. Esse entendimento passa pela análise do argumento de Cléve (1993, p. 59), de que a evolução do federalismo brasileiro é uma constante oscilação entre Estado Unitário e Federal, visto que "a cada ditadura ou regime de exceção morria o Estado Federal para ceder lugar a uma espécie de Estado Unitário não assumido". Lembramos assim, que a história do nosso federalismo tem sido marcada por oscilações entre períodos de centralização e de descentralização (REZENDE; AFONSO, 2004). Podemos exemplificar esse argumento tendo em vista o processo cíclico de centralização do poder central à luz das constituições brasileiras do período republicano.

A Constituição de 1891 assume a tendência ao federalismo dual; é fruto de uma ideologia liberal, na qual o Estado não deve intervir de modo a resguardar direitos sociais. Foi isso que aconteceu no período denominado República Velha (18911930), no qual a participação relativa ao Governo Federal na despesa pública deu sinais severos de diminuição (REZENDE; AFONSO, 2004).

Sob a luz dos argumentos de Horta (1985, p. 15), podemos dizer que, do "ângulo do constitucionalismo brasileiro, a Constituição republicana de 1891 não se afasta da ortodoxa concepção dos poderes enumerados da União [...] e dos poderes facultados ou reservados aos Estados, sem qualquer flexibilidade na partilha das competências".

Horta (1985) explica que a revisão técnica clássica da repartição de competências vai despontar na Constituição Federal de 1934, quando se registra o adensamento da competência da União, com a perda da substância legislativa dos Estados. Assim, o mecanismo compensatório, explica o autor, da legislação estadual supletiva ou compensatória é criação ordinária da Constituição Federal de 1934, que insere essa legislação na competência privativa dos Estados.

A Constituição de 1937 é outorgada e, assim, implanta a ditadura declarada da Era Vargas, cujo federalismo está na lei, porém submergido com a organização do Estado Novo. O periodo ditatorial conhecido como Era Vargas mantém o Estado federal, com uma existência meramente formal, visto que as unidades territoriais perdem sua autonomia, tornando-se submissas ao poder centralizador da União. Esse periodo, conforme assinala Soares (1997), apesar de manter formalmente o termo federativo, é marcado por um processo altamente centralizador, significando que o Estado Novo elimina a descentralização política, porém, não reduz a descentralização fiscal e administrativa, pelo contrário, determina 
maior participação das esferas subnacionais nas receitas totais do governo. Nesse periodo, os estados passam a representar, na estrutura unitária de poder, simples divisões administrativas.

A Carta de 1937, que, segundo Horta (1985, p. 16), "se afastou da forma federal, para adotar o Estado unitário descentralizado", apesar da referência nominal do Estado federal, como consta no art. $3^{\circ}$, adota ao seu estilo centralizador e autoritário a possivel atribuição, a matéria de legislação suplementar aos Estados. A inspiração centralizadora e autoritária dá à Carta o caráter de "Constituição semântica" (HORTA, 1985, p. 16, grifo do autor).

Rezende e Afonso (2004) reconhecem que as reformas sociais promovidas durante a Era Vargas são um marco na história da política social brasileira, mas a duração de sua ditadura (iniciada em 1930) provoca o renascimento das ideias liberais que levam à derrubada de Getúlio quinze anos depois (1945) de sua chegada à cena nacional. Esse modelo de governo, sustentado pela Constituição de 1937, consegue sobreviver até a promulgação da Constituição de 1946.

O Estado brasileiro regido pela Constituição de 1946 pretende retomar ao modelo federativo, para além da letra da lei, subtraido (na prática) no auge da Constituição de 1937; e busca a proteção dos direitos sociais, de forma que representa uma reação contra o estado de exceção provocado pelo centralismo do Estado Novo. Neste sentido, a Carta de 1946 amplia o leque dos direitos sociais, incluindo direitos de ordem econômica e social, direitos referentes à família, à educação e à cultura, inspirados nos ideais da solidariedade humana e nos princípios da liberdade (KELBERT, 2011). É possivel admitir que a Carta de 1946 reforça o princípio constitucional da autonomia, como sinônimo de cooperação administrativa e financeira entre os entes federados. Segundo os indicativos de Horta (1985, p 17), entendemos que a Constituição Federal de 1946 retoma a "inserção da legislação estadual ou complementar no plano das matérias de competência da União".

A Constituição de 1967 é imposta pelo Presidente da República ao Congresso Nacional, com a finalidade de dar sustentação ao governo ditatorial iniciado em 1964, deixando para trás um periodo de descentralização e de autonomia, preceitos reconquistados com o advento da Constituição de 1946. É forçoso admitir que essa Carta implanta uma república autoritária, e o federalismo fica somente nominal, como ocorrera com a outorga da Constituição de 1937. "A Constituição Federal de 1967 mantém a legislação estadual em assuntos da competência originária da União" (HORTA, 1985, p. 17-18); reduz sensivelmente a autonomia estadual e, assim, diminui a importância do poder legislativo; caracteriza-se por adotar uma feição totalitarista de governar.

Segundo Horta (1985), a descentralização de competências da União, assumida pela Carta de 1967, para beneficiar os Estados, se completaria na melhor configuração da autonomia dos Estados, mas que os poderes de organização constitucional e de legislação praticamente desaparecem na limitação imposta. Essa Carta, embora tenha sido formalmente aprovada pelo Congresso Nacional, é, na prática, outorgada pelo regime militar, impondo a retirada da importância dos estados-membros e a maior presença da União nas atividades legislativas e administrativas. À semelhança do que ocorreu com a Constituição de 1937, o texto constitucional chama o Brasil de República Federativa, contudo, nos modos do Estado unitário, pelo fato de atribuir amplos poderes ao Presidente da República e de reduzir, em alta medida, a autonomia dos estados.

O final dos anos de 1970 e início dos anos de 1980 são marcados, paulatinamente, pelo ressurgimento do debate em torno da redemocratização do Pais, sobretudo, pelo fato do regime militar dar sinais de fraqueza e por não ter conseguido levar adiante o projeto de uma obsessiva segurança nacional, assim como a institucionalização da centralização do poder nas mãos de poucos. É nesse contexto histórico que nasce a Constituição Federal de 1988, denominada por Ulisses Guimarães de "Constituição Cidadã", porque, dentre outros atributos, faz renascer consigo, o significado de federação. A Constituição da República Federativa do Brasil discorre em seu preâmbulo sobre a instituição 
do "Estado Democrático, destinado a assegurar o exercício dos direitos sociais e individuais, a liberdade, a segurança, o bem-estar, o desenvolvimento, a igualdade e a justiça como valores supremos de uma sociedade fraterna, pluralista e sem preconceitos [...]" (BRASIL, 1988).

A República Federativa do Brasil é um Estado federado, pessoa jurídica reconhecida pelo Direito Internacional, o único titular de soberania. Os entes federados - União, estados, Distrito Federal e municípios - são pessoas jurídicas de direito público interno que gozam, apenas de autonomia. O Art. $1^{\circ}$ da Carta de 1988 assim define: A República Federativa do Brasil, formada pela união indissolúvel dos Estados e Municípios e do Distrito Federal, constitui-se em Estado Democrático de Direito e tem como fundamentos: I - a soberania; || - a cidadania; III - a dignidade da pessoa humana; IV - os valores sociais do trabalho e da livre iniciativa; $\checkmark$ - o pluralismo político. Nos termos desse artigo, a Constituição Federal de 1988 adota o regime federalista como forma de organização político-administrativa, proporcionando, em alta medida, a descentralização do poder e a repartição de competências entre os entes federados.

A respeito de soberania e de autonomia, julgamos importante apresentar a distinção entre esses termos. Em Motta (2008, p. 233) absorvemos o seguinte: soberania é o "atributo que confere o poder do Estado em virtude de ser ele juridicamente ilimitado", ou seja, a soberania diz respeito ao poder político e de decisão dentro do Estado, o qual não conhece superior, pois este é o superior; autonomia é a "margem de discrição que uma pessoa goza para decidir sobre seus negócios, mas sempre delimitada essa margem pelo próprio direito", ou seja, autonomia de um governo pressupõe a elaboração de suas próprias regras e leis, sem interferência de um governo central. Significa dizer que, seja qual for a espécie de federalismo, conforme assinalam Paulo e Alexandrino (2008), devemos ressaltar que somente o Estado é soberano, não os entes federados; esses possuem apenas autonomia. A República Federativa do Brasil possui quatro espécies de entes federados dotados de autonomia: a União, os estados, os municipios e o Distrito Federal. "A recepção do municipio como elemento integrante e peculiar da federação brasileira forma o exótico sistema federativo tridimensional" (SALDANHA, 2009, p. 334). Ressaltamos que a Constituição Federal de 1988 confere ao municipio, de forma inédita, a categoria de ente federado.

Na esteira deste entendimento, Paulo e Alexandrino (2008) argumentam que, na República Federativa do Brasil, nem todos os entes federados participam da formação da vontade nacional. Os estados e o Distrito Federal têm efetiva participação, por meio de seus representantes no Senado Federal; os municipios, por seu turno, não participam, de modo algum, na formação de ordem jurídica nacional, nem atuam no processo legislativo de modificação da Constituição Federal.

A autonomia pressupõe divisão de competências: entre a União (Poder Central) e os Estados e Distrito Federal (poder regional) e, no federalismo brasileiro, com os Municípios (poder local). Essa partilha dá-se por duas técnicas principais: uma, a de reserva de matéria à União ou aos Estados (repartição horizontal); a outra, a chamada repartição concorrente (repartição vertical) (FERREIRA FILHO, 2005, p. 53). Sob a égide da Constituição Federal de 1988, a "repartição de competências não se limita ao plano da repartição horizontal da matéria legislativa, que coloca sua ênfase no processo discriminatório e faz da repartição uma demarcatória de fronteiras normativas do Estado Federal" (MOTTA, 2008, p 235). Daí, exemplifica Ferreira Filho (2005, p. 53), o poder constituido da União não pode invadir a esfera de competências dos estados, sob pena de inconstitucionalidade.

A Constituição Federal de 1988 também adota a técnica de repartição vertical de competências quando estabelece a competência concorrente no Art. 24. Isso quer dizer que a mesma matéria é deixada ao alcance de um (União) ou de outros (Estado e Distrito Federal), cabendo à União apenas estabelecer as normas gerais e aos Estadose ao Distrito Federal, estabelecer as normas suplementares (FERREIRA FILHO, 2005; MOTTA, 2008).

De acordo com as explicações de Horta (1991), a repartição de competências poderá acentuar 
a centralização, concentrando na União a maior soma de poderes, ou conduzir à descentralização, reduzindo os poderes federais e ampliando os poderes estaduais, ou ainda dosar as competências federais e estaduais, de modo a instaurar na Constituição Federal o equilibrio entre o ordenamento central e os ordenamentos parciais. Segundo Paulo e Alexandrino (2008, p. 122, grifo do autor), "a República Federativa do Brasil enquadra-se no tipo de federação de equilibrio [...]", que significa estar fundado no equilibrio entre as competências e a autonomia conferidas entre os entes federados pela Constituição Federal de 1988. Podemos citar alguns exemplos, conforme definidos na Carta de 1988: as regras constitucionais de criação das regiões de desenvolvimento entre os estados (Art. 43) e de regiões metropolitanas entre os municipios (Art. 25 , $\S 3^{\circ}$ ), de concessão de benefícios fiscais (Art. 151, l) e da repartição das receitas tributárias (Art. 157 a 159).

Em se tratando da distribuição do poder, a Constituição de 1988 registra suas competências, tanto as de natureza legislativa quanto administrativa: competência geral da União (Art. 21, I a $X X V)$, competência legislativa privativa da União (Art. 22, I a XXIX), competência comum da União, dos Estados, do Distrito Federal e dos Municipios (Art. 23, I a XII, parágrafo único), e a competência de legislação concorrente da União, dos Estados e do Distrito Federal (Art. 24, I a XVI, $\S \S 1^{\circ}$ a $4^{\circ}$ ).).

Podemos, assim, enumerar algumas considerações afirmadas por Horta (1991, p. 256) sobre repartição de competências na Carta de 1988: a) o texto constitucional supera a concepção clássica de repartição de competências fundada na distribuição de poderes da União e de poderes reservados aos Estados; b) abandona o retraimento dos textos federais anteriores, que fizeram da legislação concorrente uma simples e acanhada sub-repartição de competência dentro do grandioso quadro da competência dos poderes federais; e c) a nova repartição de competência, sem prejuizo dos poderes soberanos e nacionais da União, cria o domínio autônomo concorrente, abastecido com matérias próprias, e não com matérias deslocadas da competência legislativa exclusiva da União, como no figurino das constituições de 1934, 1946 e 1967.

Em sintese, o Estado brasileiro adota o modelo de descentralização política e administrativa, com base na repartição de competências de seus entes federados definidas na atual Constituição Federal, por isso, dotados de autonomia, ficando a soberania a cargo apenas da União; o Brasil adota o típico modelo de federação de equilíbrio, o qual se caracteriza pelo equilibrio entre as competências e a autonomia conferida aos entes federados na Constituição Federal de 1988.

Passamos, então, para a questão que diz respeito ao federalismo e ao regime de colaboração entre os entes federados no campo da educação, em conformidade com a repartição de competências conferidas nas constituições republicanas, em especial, a Carta de 1988.

\section{Federalismo e regime de colaboração na gestão da educação}

A segunda seção deste artigo propõe discutir o papel do federalismo e o regime de colaboração na implantação de políticas educacionais. Consideramos oportuno, neste caso, trazer para a discussão dois conceitos, como pano de fundo para a compreensão da relação federalismo e regime de colaboração: política social e política educacional.

A política social diz respeito aos mecanismos de gestão estatal da força de trabalho e do preço da força do trabalho, quando tratamos de uma sociedade capitalista. É, pois, entendida, a um só tempo, como contenção e ampliação dos direitos da classe trabalhadora. Em meio ao antagonismo advindo desse entendimento estão o Estado, a sociedade e o mercado. Para Shiroma, Moraes e Evangelista (2004), é estratégica a importância das políticas sociais para o Estado capitalista. Porque, por um lado, revelam as características da intervenção de um estado submetido aos interesses do capital; por outro lado, como o Estado não se define por estar à disposição de uma ou de outra classe, não se pode desobrigar dos comprometimentos com as distintas forças sociais em confronto. É neste sentido, que Faleiros (2009, p. 59) adverte que "se há um campo onde se torna necessário considerar o movimento real e concreto das forças sociais e 
da conjuntura, é o da política social".

Trazendo para o campo da política educacional, percebemos a existência dessa mesma lógica, ou seja, um campo, o qual abriga forças sociais e contradições. Sob essa convicção, Shiroma, Moraes e Evangelista (2004) reconhecem que as políticas educacionais, mesmo sob a perspectiva, muitas vezes, humanitária, comumente expressa contradições. Compreendê-las implica, além de considerar a dinâmica do movimento do capital e seus meandros, os antagônicos e complexos processos sociais com que ele se confronta, entender o projeto social do Estado e as contradições gerais do movimento histórico e a definição do perfil da educação reprodutor/ inovador da sociabilidade humana.

Esta análise nos leva a compreender que o projeto da educação brasileiro foi ao longo de sua história, principalmente no contexto do Estado federado, marcado por um perfil ora conservador e centralizador ora por um perfil democrático e descentralizador.

A Carta de 1981, a primeira no âmbito do federalismo brasileiro, expressa o regime de separação de competências entre a União e os Estados e, dessa forma, referenda, segundo Vieira (2007), o tom federalista revelando, ainda que de forma indireta, as atribuições da União em matéria de educação: o ensino superior no País e a instrução primária e secundária no Distrito Federal. Com a ausência de uma legislação de caráter nacional no campo da educação, o Governo Federal atua através de medidas dispersas durante a "Primeira República", consubstanciadas em legislação de caráter pontual. A Reforma Rocha Vaz (1925) tenta ordenar, pela primeira vez, um acordo entre o que se faz nos estados e o que se faz na União, ao menos quanto à promoção da educação primária (GHIRALDELLI JR., 2009). Fruto de uma ideologia liberal, o governo assume, segundo Cury (1996), a tônica individualista e a defesa da autonomia dos Estados e, nessa esteira, contribui para que a educação compartilhe, junto com outros temas sociais, os efeitos de um liberalismo excludente e pouco democrático. A primeira Constituição republicana, nessa tônica individualista e liberal, contenta-se, segundo Ferraz (1988), em inserir no rol das atribuições privativas do Congresso Nacional sobre o ensino superior e entre as não privativas, animar no país o desenvolvimento das letras, das artes e das ciências, criar instituições de ensino superior e secundário nos estados e prover instrução secundária no Distrito Federal. Em linhas gerais, a Constituição de 1891 no texto sobre a educação, seguindo as prerrogativas do modelo federativo, mira-se na competência legislativa da União e dos Estado.

A Constituição de 1934 é a primeira a dedicar espaço significativo à educação, embora como matéria de competência privativa à União: "Compete privativamente à União traçar as diretrizes da educação nacional (Art. 5. ${ }^{\circ}$ ). A Carta distribui as competências entre a União, Estados e Distrito Federal, demonstrado fortemente a concentração de poderes nas mãos da União, ou seja, as competências dos demais entes estão relacionadas à organização e à manutenção dos sistemas educativos, embora sem autonomia expressa (Art. 151), que Horta (1985) chama de adensamento da competência da União, com perda da substância legislativa dos Estados; apresenta dispositivos com tendência de alinhamento a um plano nacional de educação, sob a competência do Conselho Nacional de Educação; visa à criação dos sistemas educativos prevendo a destinação de recursos para a manutenção e o desenvolvimento do ensino.

Segundo Vieira (2007), a Carta de 1934, seguindo uma tendência liberal, mantém a estrutura anterior do sistema educacional, cabendo à União traçar as diretrizes da educação nacional, fixar o plano nacional de educação, organizar e manter os sistemas educativos e exercer a ação supletiva na obra educativa em todo o País. Destacamos, entretanto, que, pela primeira vez na história da educação brasileira, a Carta de 1934 traz consigo: a competência da União para traçar as diretrizes da educação nacional; o princípio, segundo o qual a educação é um direito de todos; a clareza quanto à regra de pluralidade e independência dos sistemas de ensino (FERRAZ, 1988).

A Constituição de 1937, imposta à Nação como ordenamento legal do Estado Novo, se afasta, 
segundo argumentos de Horta (1985), da forma federal para adotar a forma de Estado unitário descentralizado; neste sentido, "inverte as tendências democráticas da Carta de 1934", faz o Estado abrir mão da responsabilidade para com a educação pública, afirmando que este deveria desempenhar um papel subsidiário e não central, em relação ao ensino, enfim, não se mostra interessada em determinar ao Estado tarefas no sentido de fornecer à população uma educação geral através de uma rede de ensino público e gratuito (GHIRALDELLI JR., 2009, p. 78). Segundo argumentos de Vieira (2007), a Carta do Estado Novo é claramente inspirada nas constituições de regimes fascistas europeus; é ampliada a competência da União para fixar as bases da educação nacional, traçando diretrizes voltadas para a formação fisica, intelectual e moral da infância e da juventude (Art. 15, IX). Em alta medida, o texto constitucional de 1937 vincula a educação à iniciativa privada, fortalece a centralização dos sistemas educativos e as competências para legislar sobre a matéria.

O principal feito da Constituição de 1946 é a retomada do texto da Carta de 1934, com as atualizações necessárias, ampliando o leque dos direitos sociais, inclusive a educação e, seguindo orientações democráticas, reforça o princípio constitucional da autonomia entre os entes federados. A União tem a competência de legislar sobre as diretrizes e as bases da educação nacional, assim como organizar o sistema federal de ensino, de caráter supletivo, estendendo-se a todo o país e nos estritos limites das deficiências locais. Enquanto a Constituição de 1934 trata de traçar as diretrizes da educação nacional e a Constituição de 1937 trata de fixar as bases, traçando as diretrizes da educação nacional, a Carta de 1946 estabelece que a atribuição da União deve ser a de legislar sobre tais diretrizes, fazendo ressurgir o tema da educação como direito de todos. Vale considerar que esta Carta reparte a competência entre os entes federados (União, Estados e Distrito Federal) quanto à organização dos sistemas de ensino, cabendo à União a cooperação com auxilio financeiro em relação ao ensino primário (KELBERT, 2001; HORTA, 1985; VIEIRA, 2007; FERRAZ, 1988). Cabe ressaltar ainda, que o texto constitucional de 1946 faz uma retomada dos princípios circunscritos na Carta de 1934, assim, em matéria de educação, a competência da União, de fixar passa a legislar as diretrizes e as bases da educação nacional, cabendo aos Estados, a competência legislativa circunscrita aos seus sistemas de ensino.

Tomando um sentido contrário à Constituição anterior, a Carta de 1967 implanta uma república autoritária, de forma que o federalismo se transforma em sistema figurativo. É concebida em um cenário de supressão das liberdades políticas que, de forma direta, atinge os setores sociais, inclusive a educação. Na concepção de Vieira (2007) e Ferraz (1988), em relação à educação, os dispositivos não chegam a traduzir uma ruptura com os conteúdos de constituições anteriores, valendo-se, inclusive do modelo consagrado nas constituições de 1934 e 1946, porém, com a tendência ao fortalecimento do ensino privado, encontrando nas bolsas de estudo um dos meios para fortalecer a livre iniciativa. "Outros temas advindos dos textos nacionais de 1934, 1937 e 1946 foram reeditados, fazendo com que nos dispositivos relativos à educação a Constituição de 1967 estivesse mais próxima da LDB de 1961 do que da legislação aprovada em pleno vigor do estado de exceção" (VIEIRA, 2007, p. 302). A Constituição de 1967 mantém a competência da União para legislar sobre as diretrizes e as bases da educação nacional, acrescentando as atribuições relativas aos planos nacionais de educação.

O federalismo brasileiro, sob a égide da Carta de 1988, é chamado de federalismo de equilibrio, cuja repartição de competência dá-se de forma equilibrada entre os entes que compõem a Federação. Podemos, então, afirmar que se trata de uma comunidade juridica descentralizada, que segundo Kelsen (1998), é aquela em que o ordenamento jurídico consta de normas que apenas vigoram para dominios parcelares. Essa concepção vem da própria Carta, ao afirmar no art. 18 que a "organização político-administrativa da República Federativa do Brasil é compreen- 
dida pela União, os Estados, o Distrito Federal e os Municípios, todos autônomos" (BRASIL, 1988).

Sob esta perspectiva, a Constituição de 1988 vislumbra a repartição de competências constitucionais referentes à educação, apontando, de certa forma, para uma descentralização vertical, implicando em um modelo de federalismo de cooperação. A repartição de competências em matérias de educação aponta para o entendimento de alguns pontos, a saber: a) à União compete privativamente legislar sobre as diretrizes e as bases da educação nacional; b) é competência da União, dos Estados, do Distrito Federal e dos Municipios proporcionar meios de acesso à educação (um direito de todos, como diz o art. 205); c) compete à União, aos Estados e ao Distrito Federal concorrentemente legislar sobre a educação; e d) compete aos municípios manter, sob o regime de colaboração com a União e os Estados programas educacionais na educação infantil e no ensino fundamental. Vale aqui ressaltar que a competência privativa da União em legislar sobre as diretrizes e as bases da educação nacional decorre de um modelo de repartição horizontal de competências, onde há uma rígida determinação do que compete somente à União e, nenhuma possibilidade dos demais entes legislarem sobre a mesma matéria.

O artigo $211 \mathrm{da} \mathrm{CF} / 88\left(\S 1^{\circ}, 2^{\circ}, 3^{\circ}\right.$ e $\left.4^{\circ}\right)$ estabelece as competências de cada ente federativo: a) a União: "organizará o sistema federal de ensino e o dos Territórios, financiará as instituições de ensino público federais e exercerá, em matéria educacional, função redistributiva e supletiva, [...]"; b) os Municipios: "atuarão prioritariamente no ensino fundamental e na educação infantil"; c) os Estados e o Distrito Federal: "atuarão prioritariamente no ensino fundamental e médio"; d) a União, os Estados, o Distrito Federal e os Municipios: "na organização de seus sistemas de ensino [...] definirão formas de colaboração, de modo a assegurar a universalização do ensino obrigatório". O artigo 214 estabelece a necessidade do Plano Nacional de Educação como forma de assegurar o desenvolvimento do ensino em seus diversos níveis, etapas e modalidades por meio de ações integradas dos poderes públicos das diferentes esferas federativas.

O atual Plano Nacional de Educação com vigência de 10 anos (2014-2024), como forma de cumprir o disposto no artigo 214 da CF/88, configura-se em um instrumento de planejamento do Estado democrático de direito, que orienta a execução e o aprimoramento de políticas públicas no setor da educação. Tais políticas deverão conduzir os propósitos expressos no artigo 214: erradicação do analfabetismo; universalização do entendimento escolar; melhoria da qualidade do ensino; formação para o trabalho; promoção humanística, científica e tecnológica do país; e estabelecimento da meta de aplicação de recursos públicos em educação como proporção do produto interno bruto (BRASIL, 2014).

Vale ressaltar, entretanto, que há uma relação entre o Estado e o capitalismo e, que, portanto, as politicas educacionais acabam por absorver os reflexos dessa relação, mesmo que forma quase imperceptivel, como por exemplo: jogos de interesses, conflitos de classes, competitividade e contradições. O Estado, portanto, atua por um lado, como a instância responsável pela elaboração e implantação das políticas e, por outro lado, como apaziguador de tais conflitos e jogos de interesses. O modelo de gestão (democrática) da educação brasileira, escondido por traz do véu do neoliberalismo oculta, por vezes, pontos de contradição de seu ideário, fazendo valer políticas voltadas muito mais para a valorização do sistema capitalista do que a projeção de sua superação. Ainda assim, acreditamos que é a educação o principal mecanismo de superação das estratégias geradas e implantadas pelo capital.

\section{Considerações finais}

Este artigo teve como objetivo principal discutir sobre o modelo federalista de Estado e, nesta perspectiva, estabelecemos como especificidade do estudo, analisar o Estado federalista brasileiro e suas implicações na gestão educacional. Para fins de alcançá-lo, estabelecemos como prioridade a análise de algumas categorias, como: teorias de Estado, modelo de estado conforme organização 
administrativa, federalismo e suas especificidades, federalismo brasileiro à luz das constituições republicanas, repartição de competências em matéria de educação nas constituições republicanas.

O estudo que ora realizamos nos permite tecer algumas considerações, tais como: o federalismo no Brasil foi instituido com o advento da proclamação da República; neste regime vigoram os princípios da autonomia e da soberania; os entes federados são administrados com base no pacto federativo, ou seja, uma forma de regime de colaboração; o governo central e os governos locais são independentes entre si e soberanos em suas respectivas jurisdições, de forma que existe uma ordem jurídica central e várias ordens juridicas parciais; o federalismo brasileiro admite a figura do municipio enquanto ente federativo; a história da federação brasileira foi marcada por oscilações entre períodos de centralização e descentralização, conforme o paradigma político-administrativo, ora democrático/descentralizador ora autoritário/centralizador, refletindo, assim, na repartição de competências dos entes federados definida nas constituições federais.

No que diz respeito à categoria federalismo e regime de colaboração na gestão da educação, traçamos em linhas gerais, concepções de política social e de política educacional, considerando a dinâmica do capital como determinante dos processos de elaboração e de implantação de tais politicas.

O projeto de educação do Estado federativo brasileiro tem sido, também, marcado por um perfil ora democrático ora centralizador, seguindo a tradição dos paradigmas político-administrativo do Estado no período republicano, assim como os respectivos reflexos na repartição de competências.

A luta por uma gestão democrática da educação, pautada em políticas educacionais já mostrou avanços, isso não podemos negar, principalmente, no pós-Constituição Federal de 1988, a "Carta Cidadã", mas não podemos, de outra forma, negar que ainda é uma aspiração. A Carta de 1988 amplia os direitos sociais e a repartição de competências e inaugura o regime de colaboração entre os entes federados, como uma forma de garantir a qualidade das políticas públicas.

\section{Referências}

ABRUCIO, Fernando Luiz. A Dinâmica federativa da educação brasileira: diagnóstico e propostas de aperfeiçoamento. In: OLIVEIRA, R. P.; SANTANA, W. (org.). Educação e Federalismo no Brasil: combater as desigualdades, garantir a diversidade. Brasilia: UNESCO, 2010. p. 39-70. Disponivel em: http://unesdoc.unesco. org/images/0018/001873/187336por.pdf. Acesso em: 2 ago. 2017

ARAÚJO, Gilda Cardoso. Politicas educacionais e Estado federativo: conceitos e debates sobre a relação entre município, federação e educação no Brasil. Curitiba: Appris, 2013.

ARRETCHE, Marta. Relações federativas nas políticas sociais. Educ. Soc, Campinas, v. 23, n. 80, p. 25-48, set. 2002.Disponivel em: http://www.scielo.br/pdf/es/ v23n80/12922.pdf. Acesso em: 2 ago. 2017.

BRASIL. [Constituição de 1891]. Constituição da República Federativa dos Estados Unidos do Brasil. De 24 de fevereiro de 1891. Rio de Janeiro: Presidência da República, [1891]. Disponivel em: http://wwww.planalto.gov.br/ccivil_03/constituicao/constituicaog1.htm Acesso em: 10 ago. 2017.

BRASIL. [Constituição de 1931]. Constituição da República Federativa dos Estados Unidos do Brasil. De 16 de julho de 1934. Rio de Janeiro: Presidência da República, [1934]. Disponivel em: http://www.planalto.gov.br/ccivil_03/constituicao/constituica034.htm Acesso em: 10 ago. 2017.

BRASIL. [Constituição de 1937]. Constituição dos Estados Unidos do Brasil. De 10 de novembro de 1937. Rio de Janeiro: Presidência da República, [1937]. Disponivel em: http://www.planalto.gov.br/ccivil_03/constituicao/ constituica037.htm Acesso em: 10 ago. 2017.

BRASIL. [Constituição de 1946]. Constituição dos Estados Unidos do Brasil. Rio de Janeiro: Presidência da República, [1946]. De 18 de setembro de 1946. Disponivel em: http://www.planalto.gov.br/ccivil_03/constituicao/constituicao46.htm Acesso em: 10 ago. 2017.

BRASIL. [Constituição de 1967]. Constituição da República Federativa do Brasil de 1967. De 24 de janeiro de 1967. Brasília, DF: Presidência da República, [1967]. Disponivel em: http://www.planalto.gov.br/ccivil_03/ constituicao/constituicao67.htm Acesso em: 10 ago. 2017.

BRASIL. [Constituição de 1988]. Constituição Federativa do Brasil de 1988. De 05 de outubro de 1988. Brasília, DF: Presidência da República, [1988]. Disponivel em: http://www.planalto.gov.br/ccivil_03/Constituicao/ Constituiçao.htm. Acesso em: 1 jan. 2017.

BRASIL. Decreto n. 1 de 15 de novembro de 1889 Proclama provisoriamente e decreta como fórma de governo da Nação Brazileira a Republica Federativa, e estabelece as normas pelas quaes se devem reger os Estados Federaes. Disponível em:

http://www2.camara.leg.br/legin/fed/decret/1824-1899/decreto-1-15-novembro-1889-532625-publicacaooriginal-14.906-pe.html Acesso em: 3 ago. 2017. 
BRASIL. Plano Nacional de Educação (2014-2024). Lei n. 13.005/2014, de 25 de junho de 2014, que aprova o Plano Nacional de Educação (PNE) e dá outras providências. Brasilia: Câmara dos Deputados, Edições Câmara, 2014.

CARNOY, Martin. Estado e teoria política. Campinas, SP: Papirus, 2013.

CLĖVE, Clemerson Merlin. Temas de Direito Constitucional. São Paulo: Acadêmica, 1993

COELHO, Inocêncio Mártires. Ordenamento juridico, constituição e norma fundamental. In: MENDES, Gilmar Ferreira; COELHO, Inocêncio Mártires; BRANCO, Paulo Gustavo Gonet. Curso de Direito Constitucional. São Paulo: Saraiva, 2009. p. 1-17.

CURY, Carlos Roberto Jamil. A Educação e a primeira Constituinte Republicana. In: FÁVERO, Osmar (org.). A educação nas constituintes brasileiras (1823-1988). Campinas, SP: Autores associados, 1996. p. 69-80.

FALEIROS, Vicente de Paula. A política social do Estado capitalista. São Paulo: Cortez, 2009

FERRAZ, Ester de Figueredo. A educação nas constituições brasileiras (e nos projetos da futura constituição). Fórum educ., Rio de Janeiro, v. 12, n. 1, p. 5-16., jan./mar.1988.

FERREIRA FILHO, Manoel Gonçalves. Curso de Direito Constitucional. São Paulo: Saraiva, 2005

GARCIA, Walter E. Federalismo e gestão educativa no Brasil: notas para debate. Em Aberto, Brasilia, v. 19, n. 75. p. 70-77, jul. 2002.

GHIRALDELLI, Júnior História da educação brasileira. São Paulo: Cortez, 2009.

GRAMSCl, Antonio. Selections from prison notebooks. Nova York: International Publishers, 1971.

HOBBES, Thomas. Leviatã ou matéria, forma e poder de um Estado eclesiástico e

Civil. Traduzido por João Paulo Monteiro e Maria Beatriz Nizza da Silva. São Paulo: Abril Cultural, 1979. (Col. Os Pensadores).

HORTA, Machado Raul. Estudos de Direito Constitucional. Belo Horizonte: Del Rey, 1985.

HORTA, Machado Raul. Repartição de competências na Constituição Federal de 1988. Revista da Faculdade de Direito da Universidade Federal de Minas Gerais, Belo Horizonte, n. 33, p. 249-274, 1991. Disponivel em: https://www.direito.ufmg.br/revista/index.php/revista/article/view/1431/1360. Acesso em: 18 ago. 2017.

HOUAISS, Antônio; VILAR, Mauro de Salles. Dicionário Houaiss da Lingua Portuguesa. Rio de Janeiro: Objetiva, 2001

JOHNSON, Allan G. Dicionário de Sociologia: guia prático da linguagem sociológica. Tradução de Ruy Jungmann. Rio de Janeiro: Zahar, 1997.

LOCKE, Jonh. On civil government. Chicago: Henry Regnery, 1995.

KELSEN, Hans. Teoria geral do direito e do Estado São Paulo: Martins Fontes, 1998.
KELBERT, Fabiana Okchestein. Reserva do possivel e a efetividade dos direitos sociais no direito brasileiro. Porto Alegre: Livraria do Advogado Editora, 2011.

MARX, Karl. A ideologia alemã. São Paulo: Hucitec, 1993.

MOTTA, Sylvio. Direito Constitucional: teoria, jurisprudência e questões. Rio de Janeiro: Elsevier, 2008.

PAULO, Vicente; ALEXANDRINO, Marcelo. Resumo de Direito Constitucional: descomplicado. Niterói-RJ: Impetus, 2008

SALDANHA, Ana Cláudia. Estado federal e descentralização: uma visão crítica do federalismo brasileiro. Revista Sequência,,Florianópolis, n. 59, p. 327-360, dez. 2009

SHIROMA, Eneida Oto; MORAES, Maria Célia M. de: EVANGELISTA, Olinda. Política educacional. Rio de Janeiro: DP\&A, 2004

SOARES, Márcia Mirnda. Teoria do sistema federal: heterogeneidades territoriais, democracia e instituições políticas. 1997. Dissertação (Mestrado em Ciência Política) - Universidade Federal de Minas Gerais, Belo Horizonte, 1997.

SOUZA, Donaldo Bello; FARIA, Lia Ciomar Macedo. O processo de construção da Educação Municipal. In: SOUZA, D. B.; FARIA, L. C. M. (org.). Desafios da educação municipal. Rio de Janeiro, RJ: DP\&A, 2003. p. 107-122.

REZENDE, Fernando; AFONSO, José Roberto R. A Federação Brasileira: fatos, desafios e Perspectivas. In: ADENUAER, K. (org.). Federalismo e integração econômica regional: desafios para o MERCOSUL. Rio de Janeiro, FGV e Fórum of Federations, 2004. p. 301-362.

VIEIRA, Sofia Lerche. A educação nas constituições brasileiras: texto e contexto. Revista Brasileira de Estudos Pedagógicos, Brasilia, v. 88, n. 219, p. 291-309, maio/ago. 2007.

\section{Raimunda Maria da Cunha Ribeiro}

Doutora em Educação pela Pontifícia Universidade Católica do Rio Grande do Sul (PUCRS), em Porto Alegre, RS, Brasil; professora do curso de Pedagogia da Universidade Estadual do Piaui (UESPI), em Corrente, PI, Brasil.

\section{Endereço para correspondência}

Raimunda Maria da Cunha Ribeiro

Universidade Estadual do Piauí

Pedagogia

Rua Desembargador Amaral, 1584

Centro, 64980-000

Corrente, PI, Brasil

Os textos deste artigo foram revisados pela Poá Comunicação e submetidos para validação da autora antes da publicação. 